\title{
Chronic Skin Disease and Risk of Infection
}

\author{
Anne Braae Olesen*
}

\begin{abstract}
University Hospital of Aarhus, Department of Dermatology, Marselisborg Centret, P.P. Ørumsgade 118000 Aarhus C, Denmark
\end{abstract}

\begin{abstract}
In this paper, we review the existing knowledge on the risk of infections in chronic skin disease. The normal skin is a major physiological barrier to most microorganisms. In patients with chronic skin diseases the epidermal barrier function is disrupted and the concentration of antimicrobial peptides may be reduced. Several case series and case-control studies of selected hospitalized patients confirm a high risk of colonization with S. aureus and cutaneous infections among patients with atopic dermatitis, psoriasis, and erythroderma. Cellulitis is a common secondary skin infection associated with leg ulcer, varicose veins, lymphedema, tinea pedis, and leg dermatoses. Pox, Human papilloma, and Herpes viruses, some dermatophytes and candida albicans often give rise to secondary skin infections in chronic skin disease. Concerning infection of other organs than the skin, a few studies have shown that atopic dermatitis patients are more prone to upper and lower respiratory tract infection. One study of severe psoriasis patients has shown increased mortality due to infections. Patients with chronic skin disease may have more severe infections with prolonged periods of antibiotic treatments and worse prognosis compared with skin healthy controls, but more data from population-based studies including detailed data on relevant risk factors and confounders is needed.
\end{abstract}

Keywords: Infection, skin diseases, bacteria, epidemiologic factors.

\section{INTRODUCTION}

Skin diseases are extremely common affecting up to 20 to $30 \%$ of individuals at any one time in the general population [1]. Chronic skin diseases include common inflammatory dermatoses like atopic- and seborrheic dermatitis and psoriasis with peak incidences in childhood and young adulthood, as well as the extensive bullous diseases including bullous pemhigoid and leg ulcers with peak incidence among older adults [1]. Patients with chronic skin diseases may have an increased risk of cutaneous and other infections, but epidemiological data are limited. The aim of this review is to discuss relevant studies of the association between chronic skin disease and infections, including biological mechanisms, the risk of cutaneous infections and infections of other organs in patient with skin disease, and the prognosis of infections in these patients.

\section{GENERAL BIOLOGICAL MECHANISMS LEADING TO INFECTIONS IN PATIENTS WITH CHRONIC SKIN DISEASE}

The normal skin is a major physiologic barrier to most microorganisms. The skin resistance varies with age and gender [2]. The healthy skin surface is colonized by abundant bacterial species like Diphteroids and coagulasenegative Staphyloccocci that under normal circumstances do not lead to cutaneous infections. However, when the skin barrier function is disrupted by a chronic skin disease the microorganisms at the skin surface have direct access into

Address correspondence to this author at the University Hospital of Aarhus Department of Dermatology, Marselisborg Centret, P.P. Ørumsgade 11 8000 Aarhus C, Denmark; Tel: 0045 20296665; Fax: 0045 78461860; E-mail: Anneolse@rm.dk the skin. Massive microbial colonization may lead to subsequent clinically apparent cutaneous infection and/or through colonization of the mucous membranes may lead to infection of nearby tissues and organs.

Studies have shown that the skin protection established by keratinocytes and skin-resident T-cells is compromised in chronic skin disease and it has been suggested that this disturbance of the normal skin homeostasis leads to increased risk of infection [3]. Atopic dermatitis, which is the most frequent chronic skin disease among children in Denmark [4], often leads to colonization with StaphyloccocuS. aureus (S. aureus) in clinically normal skin [5]. S. aureus may both amplify the skin inflammation in dermatitis and may lead to worsening of the barrier defect of the skin because the exotoxins secreted by $S$. aureus act as superantigens that may penetrate the skin barrier and stimulate a Th-2 immune response which increase the inflammation of the skin [5]. Further the general susceptibility to infective agents may be increased in patients with chronic skin disease due to the drugs used for treatment and lifestyle factors, and antimicrobial resistance may be higher [6].

It has been shown that certain antimicrobial peptides are deficient in skin lesions from patients with chronic diseases like atopic dermatitis leading to an increased susceptibility to cutaneous infections $[7,8]$. In contrast to atopic dermatitis it has been suggested that psoriasis, another common inflammatory skin disease mediated by a Th-1 mediated immune response associated with local neutrophil infiltration of the skin, may protect against some cutaneous infections due to higher concentrations of antimicrobial peptides observed in skin lesions in comparison with both atopic dermatitis and healthy skin [9]. This difference of 
antimicrobial peptides in psoriasis versus atopic dermatitis may explain the observed difference in the risk of cutaneous infections with $S$. aureus $[7,8]$.

\section{CUTANEOUS INFECTIONS IN CHRONIC SKIN DISEASE}

\section{Bacteria}

Secondary bacterial infection in skin lesions is a common clinical problem [2]. Infection is most often caused by mixed bacterial flora whose origin is endogenous oral, gastrointestinal or skin $[2,10]$. Colonization means that the bacteria grow and multiply in the nutrient surface of the skin without clinical apparent infection, and infection means that multiplication within the skin leads to clinical apparent infection within the skin or deeper. Among atopic dermatitis patients, S. aureus colonizes the skin lesions in up to $90 \%$ of patients and can also colonize normal appearing skin [11]. In a case control study comparing atopic dermatitis, psoriasis, and erythroderma patients with healthy controls, S. aureus was found in $60 \%$ of psoriasis patients, $88 \%$ of atopic dermatitis patients, and $100 \%$ of erythroderma patients. In $5 \%$ of the healthy controls $S$. aureus was isolated from the nares or skin. In atopic dermatitis and psoriasis the prevalence of colonization with $S$. aureus was associated with the severity of the skin disease measured by standardised severity scores [12]. The association between colonization of $S$. aureus and severity of the skin disease is probably explained by the capability of $S$. aureus to enhance the inflammatory process in the skin by superantigenmediated T-cell activation [13].

S. aureus may also inflict clinical obvious cutaneous infection of the skin in several ways including impetigo, folliculitis and pyoderma which for example has been observed in $40 \%$ of all atopic dermatitis children in a tertiary referral dermatology clinic in South-eastern Nigeria [14]. In a Japanese case-control study among children aged 0 to 6 years that compared atopic dermatitis children with children with healthy skin, the odds ratio of having impetigo contagiosum was 1.8 (95\% CI $1.2-2.8)$ [15]. Among psoriasis patients, $S$. aureus has been found to be the predominant aerobe microorganism isolated from all body sites [2, 12]. However, in a study of 29,159 patients hospitalized from 1953 to 1983 in Germany it was observed that $30 \%$ of the atopic dermatitis patients suffered from either bacterial or viral infection while this was only found among $7 \%$ of the psoriasis patients [16]. This study led to the suggestion that patients with psoriasis have decreased risk of skin infections in comparison to atopic dermatitis patients and lead to subsequent intensive studies of the differences of antimicrobial peptides and proteins of the epithelia of patients with psoriasis, atopic dermatitis, and in some studies also healthy controls [7-9, 16, 17]. A study of the antimicrobial peptides of lesional and non-lesional skin of atopic dermatitis patients suggested that a defect in the immune defensive barrier of the epithelia and the abnormalities of the physical barrier of the epidermis together may account for the high prevalence of skin infection among atopic dermatitis patients [17]. None of above mentioned studies have adjusted for differences in confounding factors between groups, including lifestyle factors, past or present topical and systemic treatments of the underlying skin disease, and use of antibiotics.

In addition to $S$. aureus, group A streptoccocci like Streptococcus pyogenes also frequently leads to infection of the skin [18]. Skin lesions close to the mucous membranes have been shown to be predominantly infected with microorganisms from these membranes and enteric gramnegative bacilli and Bacteroides species are most often isolated from skin lesions of the buttock and legs [2, 10, 18]. Cellulitis is a common secondary cutaneous infection among patients with chronic skin diseases. The skin diseases at increased risk of cellulitis have been studied in several case and case-control studies and include chronic leg ulcer of all causes, varicose veins of the leg, lymphedema, tinea pedis, and leg dermatoses [19-21]. Risk factors for recurrency of cellulitis have been studied in a study including 574 patients hospitalized with erysipelas. Recurrency occurred mainly in men (56.9 percent, $\mathrm{p}<0.001)$ in the lower limb (80.7 percent) and was associated with venous insufficiency $(\mathrm{p}<0.003)$, lympedema $(0.04)$, acute trauma $(\mathrm{p}<0.02)$ and tinea pedis $(\mathrm{p}<0.003)[21]$.

\section{Viruses}

The normal skin is a tough and impermeable barrier to the entry of many viruses. Some viruses like pox viruses, papilloma- and herpes viruses may enter through small abrasions of the skin and these virus particles are present in high titre in skin lesions. They spread with direct contact from these lesions, enabling further spreading of the infection locally or lead to infection in another host [22].

In a Japanese case-control study the odds ratio for molluscum contagiosum infection (pox virus) was $1.6(95 \%$ CI 1.0-2.7) among children with atopic dermatitis aged 0 to 6 years compared to children with healthy skin [15]. In another study of the epidemiology of molluscum contagiosum among children in a tertiary pediatric dermatology referral centre, $1 / 4$ of all patients had a history of previous or active coexistent atopic dermatitis [23]. The children with atopic dermatitis had increased number of molluscum contagiosum lesions (37\% had more than 30 lesions) compared to other children of the dermatology referral centre $(24 \%$ with more than 30 lesions) [23]. Molluscum contagiosum infection is more persistent in patients with chronic skin disease and may more often induce further infective complications and scarring [24]. In a study among atopic dermatitis children in a tertiary referral skin centre in Singapore, $19 \%$ of the children had secondary bacterial cutaneous infections and $3 \%$ had complicating viral infections of the skin, primarily eczema herpeticum, viral warts and molluscum contagiosum. However, as in many studies there were no controls for comparison [25].

Eczema herpeticum is caused by infection with Herpes simplex virus spreading from the primary infection or a flare up of a herpes infection creating a severe superinfection on eczematous skin [26]. It most commonly starts with a simple recurrent labial cold sore infection, developing rapidly from vesicles into pustules and punched out crusts in the facial area to the entire body, accompanied by fever, malaise and lymphadenopathy [27]. The infection is most often observed in the second or third decade of life. It is most common among patients with moderate to severe chronic eczema 
disease, of which the majority has been described as untreated for their chronic skin disease [26-29]. One study has investigated the subset of atopic dermatitis patients who had previous eczema herpeticum in comparison with atopic dermatitis patients without previous eczema herpeticum. The eczema herpeticum positive patients had much more frequently cutaneous infections with $S$. aureus and pox virus compared to the eczema herpeticum negative atopic dermatitis patients $(78 \%$ versus $8 \%$ ). The authors of the study found that the eczema herpeticum positive atopic dermatitis patients had a more severe Th-2-polarized disease compared with the atopic dermatitis patients without previous eczema herpeticum [30]. Further it has been shown that the lower levels of antimicrobial peptides in the epidermis in atopic dermatitis contributes to the increased susceptibility to some of the specific viral attacks of the skin observed among the chronic atopic dermatitis patients [27].

\section{Fungi}

Only a few molds and yeasts cause disease in humans. The most common infections are the superficial infections of the skin, hair and nails, which may be rather chronic and relatively resistant to treatments but rarely affect the general health of the patient [31].

Malassezia yeasts are a normal part of skin flora but may have a causative role in seborrheic dermatitis and have been associated with the chronic head and neck dermatitis in atopic dermatitis $[32,33]$. In a case-control study of atopic dermatitis cases and skin healthy controls it was shown that Malasezzia sympodialis can trigger the innate immune response through an increased antimicrobial peptide (LL-37) secretion increasing the inflammation of the skin and severity of the skin disease among atopic dermatitis patients [34].

Dermatophytes especially Trichophyton rubrum are more common causes of onychomycosis in toenails in psoriasis patients (48\%) compared to skin healthy controls (28\%) $(p<0.005)$ [35]. This observation has been confirmed in a multicenter study in which the risk of psoriasis patients having onychomycosis was $56 \%$ higher than among age and gender matched non-psoriatic patients $(\mathrm{p}<0.02)$ [36]. The second most common toenail onychomycosis among psoriasis patients is due to candida yeasts [35]. A comparison of mycoses in patients with atopic dermatitis and psoriasis has been performed among 40,000 in-patients of the Department of Dermatology of Kiel, Germany. This study showed a significantly decreased occurrence of tinea among psoriasis and atopic dermatitis patients in comparison with other hospitalized patients of the Dermatological Department $(\mathrm{RR}=0.13, \mathrm{p}<0.01)$ [37].

Candida albicans is part of the normal microflora of the mucous membranes in the respiratory, gastrointestinal and female genital tracts [31]. In the study of candida infections among hospitalized patients of the Department of Dermatology of Kiel it was observed that patients with dermatomyositis, bullous pemphigus, tinea inguinalis and condylomata acuminata had a threefold increase of candida infections of the skin. Among urticaria, folliculitis and bullous pemphigoid patients, candida infection were observed more than twice as often than expected [38]. A comparison of Candida albicans colonization of the tongue, in the axillae and the groin has been performed among patients with psoriasis, atopic dermatitis and healthy skin controls [39]. A significantly higher prevalence of candida colonization in psoriatic patients was observed on the tongue $(32 \%)$ but not in the axillae or groin. However, candida colonization of the tongue was asymptomatic and it was concluded that this was a clinically irrelevant finding [39].

\section{INFECTIONS OF OTHER ORGANS THAN THE SKIN}

\section{Respiratory Tract Infections}

Patients with chronic skin disease may be prone to systemic infections for many reasons. The infective agents that colonize the skin with increased frequency may migrate to other organs through the mucous membranes or enter through small abrasions of the skin to the blood. The host susceptibility to infective agents may be further enhanced by the comorbidity often associated with the chronic skin disease. As an example, atopic dermatitis patients are prone to other atopic disease manifestations in the airways; i.e., asthma and allergic rhinitis [40]. Pyoderma gangrenosum patients may have underlying inflammatory bowel disease, rheumatoid arthritis or leukemia.

A study from Sweden compared 955 adult atopic dermatitis cases with non-atopic controls, and found that the risk of upper respiratory tract infections was increased among atopic dermatitis cases $(12.9 \%)$ versus non-atopic controls $(7.5 \%)(p<0.05)$ [41]. In a prospective study of a birth cohort of 4089 children in Sweden, it was observed that there was a substantially increased risk of lower respiratory tract infections among children with atopic dermatitis during the first and second year of life (risk ratio 2.2; 95\% CI 1.14.2) [40]. A stratification for asthma did not markedly change the increased risk of pneumonia among the atopic dermatitis children, indicating that the increased risk was not a consequence of the higher incidence of asthma among the atopic dermatitis patients [40]. These results were confirmed in a case-control study from Poland showing that there was a significantly increased risk of pneumonia $(p<0.01)$ and bronchitis $(\mathrm{p}<0.001)$ among atopic dermatitis children born in 2005 to 2008 in comparison to age- and gender-matched controls in a general practice [42].

\section{Urinary Tract Infections}

Two studies have evaluated the risk of urinary tract infection among patients with infantile atopic dermatitis. A study from Italy observed that bacteriuria and leukocyturia were present among $28 \%$ of atopic dermatitis infants in comparison to only $3 \%$ of controls [43]. These findings were confirmed in a similar study from Iran [44].

\section{Other Infections and the Prognosis of Infections}

One study has investigated the occurrence of infective endocarditis among patients hospitalized in a dermatology department during a period of 12 months from 2006 to 2007 [45]. In this study, 7 patients were diagnosed with endocarditis. In 6 out of 7 cases, the skin was the source of the infective agent. It was concluded that the main risk factors for infective endocarditis among these dermatological patients were chronic dermatosis and invasive cutaneous procedures involving lesional skin. In a Japanese study, 25 atopic dermatitis patients were followed up after open heart 
surgery. Three patients developed methicillin-resistant $S$. aureus mediastinitis after median sternotomy [46].

Studies of severe infections and the prognosis of these infections are sparse among patients with chronic skin disease. A recent population based cohort study of the causespecific mortality among patients with severe psoriasis observed an increased mortality due to infections with a hazard ratio of $1.65(95 \% \mathrm{CI} 1.26-2.18)$ [47]. The definition of severe psoriasis in this study was defined according to the prescription of phototherapy including psoralen and UVA or systemic immunosuppressive treatment. The study gives no clear answer if the increased infection-specific mortality was caused by the chronic skin disease itself, associated comorbidities, lifestyle factors, the treatment of the chronic skin disease, or interaction of several of these factors [47].

One case description of Darier's disease, which is a rare hereditary universal erosive skin eruption, describes the course of a severe secondary cutaneous infection with mixed bacteria and recurrent eczema herpeticum. The patient finally died of sepsis and dehydration with acute renal failure after development of severe hypoalbuminemia [48]. Several such case series have been published, describing particularly severe infections with increased risk of complications or mortality among patients with severe chronic skin diseases. These case reports are in accordance with my personal clinical experience, but sound epidemiological evidence from comparative studies is limited.

\section{CONCLUSION}

Cutaneous infections are commonly observed in patients with chronic skin diseases. $S$. aureus is the most prevalent aerobe bacteria isolated in secondary infected skin lesions. Pox, Human papilloma and Herpes viruses, a few molds and yeasts seem to infect the skin of patients with chronic skin diseases more frequently than that of other individuals.

The risk increase may differ according to type of chronic skin disease; i.e., atopic dermatitis patients are more prone to infections with $S$. aureus compared to psoriasis patients. There is some evidence that atopic dermatitis patients have increased risk of upper and lower respiratory tract infections, and that psoriasis patients treated with immune-suppressive drugs have increased mortality due to infections. More data from comparative population-based studies including detailed confounder data is needed to elucidate the risk of infections secondary to chronic skin disease and infection prognosis in these patients.

\section{CONFLICT OF INTEREST}

Leo Pharma Denmark has covered travel expenses to the American Academy of Dermatology Conference, San Diego, 2012.

\section{ACKNOWLEDGEMENT}

Special thanks to Professor Lars Iversen, Aarhus University Hospital for relevant discussion concerning the role of antimicrobial peptides in skin homeostasis and to associate professor Reimar Wernich Thomsen, Aarhus University Hospital for editorial help in the revision of the paper.

\section{REFERENCES}

[1] Rea JN, Newhouse ML, Halil T. Skin disease in Lambeth. A community study of prevalence and use of medical care. Br J Prev Soc Med 1976; 30: 107-14.

[2] Brook I. Secondary bacterial infections complicating skin lesions. J Med Microbiol 2002; 51: 808-12.

[3] Di MP, Perera GK, Nestle FO. The multitasking organ: recent insights into skin immune function. Immunity 2011;35: 857-69.

[4] Olesen AB, Bang K, Juul S, Thestrup-Pedersen K. Stable incidence of atopic dermatitis among children in Denmark during the 1990s. Acta Derm Venereol 2005; 85: 244-7.

[5] Elias PM, Schmuth M. Abnormal skin barrier in the etiopathogenesis of atopic dermatitis. Curr Opin Allergy Clin Immunol 2009; 9: 437-46.

[6] Niebuhr M, Mai U, Kapp A, Werfel T. Antibiotic treatment of cutaneous infections with StaphylococcuS. aureus in patients with atopic dermatitis: current antimicrobial resistances and susceptibilities. Exp Dermatol 2008; 17: 953-7.

[7] Gambichler T, Skrygan M, Tomi NS, et al. Differential mRNA expression of antimicrobial peptides and proteins in atopic dermatitis as compared to psoriasis vulgaris and healthy skin. Int Arch Allergy Immunol 2008;147:17-24.

[8] Ong PY, Ohtake T, Brandt C, et al. Endogenous antimicrobial peptides and skin infections in atopic dermatitis. $\mathrm{N}$ Engl $\mathrm{J}$ Med 2002; 347: 1151-60.

[9] Nomura I, Goleva E, Howell MD, et al. Cytokine milieu of atopic dermatitis, as compared to psoriasis, skin prevents induction of innate immune response genes. J Immunol 2003; 171: 3262-9.

[10] Brook I: Role of oral bacteria. Pediatr Infect Dis J 1991; 10: 628.

[11] Cho SH, Strickland I, Boguniewicz M, Leung DY. Fibronectin and fibrinogen contribute to the enhanced binding of StaphylococcuS. aureus to atopic skin. J Allergy Clin Immunol 2001; 108: 269-74.

[12] Tomi NS, Kranke B, Aberer E. Staphylococcal toxins in patients with psoriasis, atopic dermatitis, and erythroderma, and in healthy control subjects. J Am Acad Dermatol 2005; 53: 67-72.

[13] McFadden JP, Noble WC, Camp RD. Superantigenic exotoxinsecreting potential of staphylococci isolated from atopic eczematous skin. Br J Dermatol 1993; 128: 631-2.

[14] Nnoruka EN. Current epidemiology of atopic dermatitis in southeastern Nigeria. Int J Dermatol 2004; 43: 739-44.

[15] Hayashida S, Furusho N, Uchi H, et al. Are lifetime prevalence of impetigo, molluscum and herpes infection really increased in children having atopic dermatitis? J Dermatol Sci 2010; 60: 173-8.

[16] Christophers E, Henseler T. Contrasting disease patterns in psoriasis and atopic dermatitis. Arch Dermatol Res 1987; 279 (Suppl): S48-51.

[17] Hata TR, Gallo RL. Antimicrobial peptides, skin infections, and atopic dermatitis. Semin Cutan Med Surg 2008; 27: 144-50.

[18] Jawetz E, Melnick JL, Adelberg EA, Brooks GF, Butel JS, Ornston LN, Eds. Medical Microbiology. Pathogenesis of Bacterial Infection \& Host Resistance to Infection. London: Prentice-Hall International Inc, 1989; pp. 126-42.

[19] Bartholomeeusen S, Vandenbroucke J, Truyers C, Buntinx F: Epidemiology and comorbidity of erysipelas in primary care. Dermatology 2007; 215: 118-22.

[20] Dupuy A, Benchikhi H, Roujeau JC, et al. Risk factors for erysipelas of the leg (cellulitis): case-control study. BMJ 1999; 318: 1591-4.

[21] Pavlotsky F, Amrani S, Trau H. Recurrent erysipelas: risk factors. J Dtsch Dermatol Ges 2004; 2: 89-95.

[22] Jawetz E, Melnick JL, Adelberg EA, Brooks GF, Butel JS, Ornston LN, Eds. Medical Microbiology. Pathogenesis \& Control of Viral Diseases. London: Prentice-Hall International Inc 1989; pp. 37387.

[23] Dohil MA, Lin P, Lee J, Lucky AW, Paller AS, Eichenfield LF. The epidemiology of molluscum contagiosum in children. J Am Acad Dermatol 2006; 54: 47-54.

[24] Ghura HS, Camp RD. Scarring molluscum contagiosum in patients with severe atopic dermatitis: report of two cases. Br J Dermatol 2001; 144: 1094-5.

[25] Tay YK, Khoo BP, Goh CL. The epidemiology of atopic dermatitis at a tertiary referral skin center in Singapore. Asian Pac J Allergy Immunol 1999; 17: 137-41. 
[26] Wollenberg A, Zoch C, Wetzel S, Plewig G, Przybilla B. Predisposing factors and clinical features of eczema herpeticum: a retrospective analysis of 100 cases. J Am Acad Dermatol 2003; 49: 198-205.

[27] Bussmann C, Peng WM, Bieber T, Novak N. Molecular pathogenesis and clinical implications of eczema herpeticum. Expert Rev Mol Med 2008; 10: e21.

[28] Peng WM, Jenneck C, Bussmann C, et al. Risk factors of atopic dermatitis patients for eczema herpeticum. J Invest Dermatol 2007; 127: $1261-3$

[29] Wollenberg A, Wetzel S, Burgdorf WH, Haas J. Viral infections in atopic dermatitis: pathogenic aspects and clinical management. J Allergy Clin Immunol 2003; 112: 667-74.

[30] Beck LA, Boguniewicz M, Hata T, et al. Phenotype of atopic dermatitis subjects with a history of eczema herpeticum. J Allergy Clin Immunol 2009; 124: 260-9, 269.

[31] Mitchell TG. Medical Mycology. In: Jawetz E, Melnick JL, Adelberg EA, Brooks GF, Butel JS, Ornston LN, Eds. Medical Microbiology. London: Prentice-Hall International Inc. 1989; pp. 294-314.

[32] Gupta AK, Bluhm R. Seborrheic dermatitis. J Eur Acad Dermatol Venereol 2004;18:13-26.

[33] Gupta AK, Batra R, Bluhm R, Boekhout T, Dawson TL Jr. Skin diseases associated with Malassezia species. J Am Acad Dermatol 2004; 51: 785-98.

[34] Agerberth B, Buentke E, Bergman P, et al. Malassezia sympodialis differently affects the expression of LL-37 in dendritic cells from atopic eczema patients and healthy individuals. Allergy 2006; 61: 422-30.

[35] Leibovici V, Hershko K, Ingber A, Westerman M, Leviatan-Strauss $\mathrm{N}$, Hochberg M. Increased prevalence of onychomycosis among psoriatic patients in Israel. Acta Derm Venereol 2008; 88: 31-3.

[36] Gupta AK, Lynde CW, Jain HC, et al. A higher prevalence of onychomycosis in psoriatics compared with non-psoriatics: a multicentre study. Br J Dermatol 1997; 136: 786-9.

[37] Henseler T. Tausch I. Mycoses in patients with psoriasis or atopic dermatitis. Mycoses 1997; 40 (Suppl 1): 22-8.
[38] Henseler T. Mucocutaneous candidiasis in patients with skin diseases. Mycoses 1995; 38 (Suppl 1): 7-13.

[39] Leibovici V, Alkalay R, Hershko K, et al. Prevalence of Candida on the tongue and intertriginous areas of psoriatic and atopic dermatitis patients. Mycoses 2008; 51: 63-6.

[40] Bohme M, Lannero E, Wickman M, Nordvall SL, Wahlgren CF. Atopic dermatitis and concomitant disease patterns in children up to two years of age. Acta Derm Venereol 2002; 82: 98-103.

[41] Rystedt I, Strannegard IL, Strannegard O. Recurrent viral infections in patients with past or present atopic dermatitis. $\mathrm{Br} \mathrm{J}$ Dermatol 1986; 114: 575-82.

[42] Frankowska J, Kamer B, Trznadel-Budzko E, Rotsztejn H. The retrospective evaluation of pneumonia and bronchitis cases in infants and small children with atopic dermatitis in the practice of a family doctor - personal observations. Adv Med Sci 2010; 55: 2503.

[43] Oggero R, Monti G, Fiz A, Tonetto P, Mostert M. Atopic dermatitis of infancy and urinary tract infections. Dermatology 1994; 189: 139-41.

[44] Farajzadeh S, Ghazanfari F, Esfandiarpour I, Shahesmaeili A, Rahnama Z, Aghaei $\mathrm{H}$. The relationship between infantile atopic dermatitis and urinary tract infection. Iran J Allergy Asthma Immunol 2009; 8: 211-4.

[45] Konstantinou MP, Valeyrie-Allanore L, Lesprit P, et al. [Infective endocarditis in a dermatology unit]. Ann Dermatol Venereol 2009; 136: 869-75.

[46] Fukunaga N, Yuzaki M, Shomura Y, Fujiwara H, Nasu M, Okada Y. Clinical outcomes of open heart surgery in patients with atopic dermatitis. Asian Cardiovasc Thorac Ann 2012; 20: 137-40.

[47] Abuabara K, Azfar RS, Shin DB, Neimann AL, Troxel AB, Gelfand JM. Cause-specific mortality in patients with severe psoriasis: a population-based cohort study in the U.K. Br J Dermatol 2010; 163: 586-92.

[48] Okada E, Nagai Y, Motegi S, Tamura A, Ishikawa O. Fatal case of Darier's disease with recurrent severe infections. Acta Derm Venereol 2009; 89: 408-9.

(c) Anne Braae Olesen; Licensee Bentham Open.

This is an open access article licensed under the terms of the Creative Commons Attribution Non-Commercial License (http: //creativecommons.org/licenses/by$\mathrm{nc} / 3.0 /$ ) which permits unrestricted, non-commercial use, distribution and reproduction in any medium, provided the work is properly cited. 